\title{
LA EPÍSTOLA DE CETINA A DON DIEGO HURTADO DE MENDOZA
}

\author{
José Manuel Rico García
}

El presente trabajo se propone estudiar la epístola de Cetina a Don Diego Hurtado de Mendoza y su significación en la producción epistolar del poeta sevillano. Tal propósito pretende analizar en qué modo las características estilísticas, métricas y estructurales de esta composición pueden contribuir a la definición y caracterización de un género tan complejo como ambiguo: la epístola poética.

Las dificultades que ello implica ya fueron puestas de manifiesto por la bibliografía dedicada al estudio de la epístola poética del siglo XVI [Elías L. Rivers (1954) y Claudio Guillén (1972)]. En primer lugar, hay que tener en cuenta que los poetas del XVI, desde Garcilaso, que ensayan la epistola poética, no cuentan con un tratado de preceptiva literaria hasta 1580, con el Arte Poética Castellana de Sánchez de Lima. Asimismo, la escasa consideración que las preceptivas y tratados de poética en general tuvieron para con la epístola demuestra que este género no ha tenido teorizadores ni historiadores que clarificaran su desarrollo. Si a esto añadimos la falta de un preciso modelo clásico de imitación, podemos decir que la historia del desarrollo de la epístola en el siglo de oro ha sido un camino de experimentación con tanteos e incertidumbres, en definitiva, el ensayo de un género literario.

La revisión del corpus epistolar de la obra de Cetina nos conduce directamente al centro de los problemas planteados en la definición del género epistolar. Begoña López Bueno, en su estudio de conjunto ${ }^{1}$ sobre la vida y la obra del autor sevillano, fija en 16 el número de epístolas escritas por Cetina: catorce publicadas por Hazañas ${ }^{2}$ y dos por Lucas de Torre; desestimando en su cataloga-

1 LÓPEZ BUENO, Begoña: Gutierre de Cetina, Poeta del Renacimiento, Sevilla, 1978, págs. 257-261.

2 HAZAÑAS Y LA RUA, Joaquín: Obras de Gutierre de Cetina, Sevilla, 1985. 
ción tres de las publicadas por Hazañas: I, VII y IX. Nos propone la siguiente clasificación:

A) De intimidad personal.

B) Otros temas.

C) Traducciones.

Si hacemos una somera revisión de las incluidas en el primer grupo, observaremos que estas composiciones ni siquiera responden a la modalidad epistolar, ya que en ellas, como señala Begoña López, «la relación establecida entre autordestinatario es de diversos grados, pero a menudo las epístolas están más dedicadas que dirigidas». La mayor parte de estas composiciones pueden ser consideradas auténticas elegías amorosas. Así, en la epístola II —-seguimos la numeración de Hazañas - el poeta se dirige a la amada definiendo el género elegíaco de la composición: «la mano del dolor guía la pluma» (v. 28). Igualmente, en la epistola IV, encontramos este terceto:

$$
\begin{aligned}
& \text { «Consiéntese quejar la pena mía } \\
& \text { De Dórida me quejo, a ella escribo } \\
& \text { Nadie sabe quién es, ni lo sabría». }
\end{aligned}
$$

En la misma línea se encuentran, la X: «Señora ya el dolor, no me consiente» o la número XV: «Ya señora, se van como los días». Todas ellas responden al arrebatado análisis de los sentimientos y a la cruel introspección psicológica que le son propias a la elegía. En este grupo tenemos otras tres composiciones bajo el nombre de epístolas que responden a las mismas características que las anteriores.

Este grupo de tres epístolas se aproximan al menos a la modalidad epistolar, al ser dirigidas y no dedicadas a alguien que se convierte en confidente de las desdichas amorosas del poeta. Son las dirigidas a la princesa de Molfeta, al señor Pabordre Gualbes y a don Jerónimo de Urrea. Esta última es ejemplo de una de las formas que adoptó la epístola en esta época de experimentación; nos referimos a la epístola pastoril. Aquí, Cetina se viste de los ropajes de Vandalio y se dirige al pastor Iberio (Don Jerónimo de Urrea) confesándole su mal de amor. En su forma pastoril las epístolas generalmente tienen contestación del destinatario -igualmente en el marco pastoril-. En estos casos el tono elegíaco llega a la altura de los debates amorosos propios de la égloga, recogiéndose, de este modo, el sentido dramático de ésta en el diálogo establecido por el principio epistolar. Piénsese en el intercambio de epístolas entre Ramírez Pagán y Montemayor.

Nos encontramos, pues, con siete composiciones denominadas epístolas que pueden ser consideradas, en sentido estricto, como elegías. Epístola y elegía coinciden en su procedimiento: ambas se dirigen a un destinatarios o bien están dedicadas a alguien. Pero tal recurso estructural lo podemos rastrear en sonetos, sátiras, epigramas, canciones, etc. Bastaría con leer el arranque de la elegía II de Garcilaso para constatar cómo el procedimiento epistolar informa las composiciones elegíacas, así lo señaló Keniston e insistió Claudido Guillén más recientemente ${ }^{3}$.

3 GUILLÉN, Claudio: «Sátira y poética en Garcilaso», enHomenaje a Casalduero, Madrid, 1972, pág. 218. 
Refiriéndose a las Heroidas de Ovidio, señala Claudio Guillén que éstas son "un factor sin el cual no cabe entender la proximidad de la elegía a la epístola» ${ }^{4}$. Las Heroidas, cartas imaginadas que las heroínas de la antigüedad envían a sus amantes, gozaron de una notable difusión tanto en la Edad Media como en el Renacimiento. En España, gran parte de las Heroidas se incluyen en la General Estoria de Alfonso X; ya observó Claudio Guillén la ostensible conexión entre las composiciones ovidianas y las novelas sentimentales de forma epistolar, más «que con la elegía y la poesía amorosa del siglo XVI». No obstante, entre estas conexiones con la poesía amorosa, habría que espigar las tres traducciones en tercetos que Gutierre de Cetina hace de la Heroida I: «Epístola de Penélope a Ulises»; de la Heroida II: «Epístola de Filis a Demofón»; y de la Heroida VII: «Epístola de Dido a Eneas». Cetina llama a estas tres traducciones epístolas. La causa de esta denominación es, una vez más, el procedimiento epistolar utilizado en estas pseudocartas o cartas imaginarias. Algo semejante ocurre en Francia en tres casos de particular relieve. El primer caso al que nos referimos es el de Chaucer, quien en la Leyenda de las Claras Mujeres, obra de 1465, llama a las heroidas ovidianas epístolas. Los otros dos casos son notados por Claudio Guillén en su artículo. En primer lugar el de Marot, quien publica la epístola de Maguelonne que es una heroida. La otra obra especialmente significativa es Epitres Morales et Familières de Jean Bouchet de 1545; en ella se incluyen tanto cartas familiares como heroidas.

Estas conexiones, convergencias, deslizamientos y contactos entre unos géneros y otros sólo pueden responder a la confusión originada por el intento de asimilación de los géneros clásicos que se está formalizando en el siglo XVI. De ahí la necesidad de tratar a muchas de estas composiciones como tanteos a meros ensayos en los géneros clásicos. Esta tendencia responde a un espíritu de época, a una coyuntura especial que nos permite observar estos hechos en cualquier literatura.

Hemos visto con la intensidad que la confusión entre epístola, heroida y elegía se da en Francia. Sin embargo, aunque menos acentuadamente, esto sucede también en España, y Cetina es un claro ejemplo de tal desconcierto, con las siete elegías a las que llama epístola y las tres traducciones de las heroidas ovidianas denominadas igualmente epístolas.

El caso de la atribución de los tercetos que empiezan «si aquel dolor que da al sentir la muerte» puede ser un índice aclaratorio de la confusión que tratamos. Esta composición aparece en un mismo manuscrito dos veces, una vez atribuida a Cetina y otra a Diego Hurtado de Mendoza, en ambas ocasiones con el título «Epístola a una partida». Pero, curiosamente, se encuentra también entre las poesías de Don Hernando de Acuña, impresas en Madrid en 1951, con el título «Elegía a una partida».

De la confusión o indefinición del género epistolar se hacen eco los primeros teorizadores poéticos. Si en Francia, como escribe Claudio Guillén, «el desconcierto de los primeros teóricos, en lo que toca a la distinción entre epístola y ele-

4 Ibíd., pág. 224. 
gía, es absoluto» ${ }^{5}$, en España no va a ocurrir menos. En la II epístola del Ejemplar Poético de Juan de la Cueva podemos leer los siguientes versos:

$$
\begin{aligned}
& \text { y lo primero que advertir debemos } \\
& \text { que la epístola abunda de argumentos } \\
& \text { varios, donde ampliamente la ocupemos. } \\
& \text { Sirve para amorosos sentimientos, } \\
& \text { casi como la elegía,... }
\end{aligned}
$$

La imprecisión del adverbio casi es el espejo gramático donde se refleja cuanto venimos diciendo.

La cita del Ejemplar de Cueva no tiene desperdicio:

Y lo primero que advertir debemos que la epístola abunda de argumentos varios,

Seguidamente dirá:

Cosas de ella de placer se canta sucesos en viajes dilatados y a varias digresiones se adelanta Son a chacota y a mofa dedicados los versos della y pueden si agradare ser en mordientes sátiras usados

(364-369)

«Casi como la elegía», «abunda de argumentos varios», «varias digresiones», «a chacota y mofa» dedicados sus versos y pueden ser «mordientes sátiras». Ante esta desordenada enumeración de las posibilidades de la epístola que el Ejemplar relata, sólo podemos preguntarnos qué era la epístola para Cueva. En la conciencia del autor del Ejemplar Poético está impresa la idea de la epístola como un género que, por la virtualidad que le otorga el procedimiento dialogístico del autor con un interlocutor a quien va dirigida o dedicada la composición, abraza a otros géneros que disfrutan del mismo procedimiento: elegía, capítulo, sátira... Sin embargo la falta de concreción que acusa Cueva es completamente irreprochable, pues él sólo cuenta para confeccionar la «indefinición del género» con los datos que le han proporcionado las epístolas que ha leído de sus contemporáneos y las que él mismo ha escrito.

Cueva no cuenta con el abrigo de un precedente teórico entre las nuevas preceptivas, ya que éstas han ignorado a la epístola o bien la han tratado indirectamente. A nuestro entender la penetración de unos géneros en otros, difuminando sus lindes, obedece, insistimos, a la novedad y bisoñez de estos ensayos poéticos, cuya característica, esencial a todos, es el procedimiento epistolar. Pero esto no sería determinante, pues de lo contrario, la identificación de géneros sería am-

5 Ibíd., pág. 225.

6 Ed. de Francisco A. de Icaza, Espasa Calpe, Madrid, 1973. 
pliable a epigramas, sonetos, odas y otras composiciones que estuvieran marcadas por el encabezamiento «dirigidas a» o «dedicadas a».

La métrica; el terceto, metro común a elegías, epístolas, sátiras, capítulos y églogas, se constituye en el actante que determina la identificación de estos géneros. No es posible ahondar a la historia del desarrollo del terceto en Italia y la peripecia de su adaptación en España. Joaquín Arce ${ }^{7}$ nos ofrece un detallado análisis del desarrollo del terceto en su extraordinaria obra Literaturas Italiana y Española Frente a Frente.

$\mathrm{El}$ terceto nace con la forma silogística del modo de razonar escolástico. Este metro responde a la peculiar concepción poética del modo y su expresión en Dante. Siguiendo el asendereado camino que abrió Dante, los poemas alegóricodidácticos del siglo XIV en Italia adaptarán el terceto: El Ditamondo de Fazio degli Uberti o la Amorosa Visione del Bocaccio. Pero, como señala J. Arce, con Petrarca el terceto extiende su campo de acción «de lo didáctico a lo histórico y discursivo, la terzina se convierte en el molde adecuado de toda clase de narraciones y enumeraciones» ${ }^{8}$.

A fines del XV Lorenzo el Magnífico lo utilizará en sus églogas. Después Sannazaro lo adoptará en ocho de las doce que comprende su Arcadia.

Finalmente Ariosto clarificará la situación, sintetizando la tendencia del pasado siglo, eligiendo la octava real como metro épico y heroico y el terceto para sus sátiras.

De otro lado, la presencia del capítulo viene a enturbiar más este difícil desarrollo del terceto. El nombre de capítulo explica la transformación que ha sufrido el terceto dantesco en su evolución. Tanto los cantos de la Divina Comedia como las partes de que consta cada triunfo del Petrarca se llamaron Capitoli. De aquí se extendió la denominación de Capitolo ternario a toda composición escrita en tercetos, con argumento vario, aunque inclinado a lo burlesco por la intención de parodia con que surgió; pero también de carácter didáctico-moral, político e histórico. «Así — escribe J. Arce- queda reducida, la que fue estrofa alegóricodantesca, a la mera confidencia, a los afectos tenues y familiares, a la disertación amistosa e incluso a la censura. En otras palabras, desvirtuado su sentido originario, el terceto se convierte en el metro propio de la epístola, de la sátira, de la elegía y del capítulo» ${ }^{9}$.

En tales circunstancias y con tal abanico de posibilidades reciben y adaptan el terceto nuestros poetas, si bien, conscientes de la transformación que este metro había sufrido en Italia, como aclara Boscan en su carta a la duquesa de Soma: «Dante fue más atrás: el qual usó muy bien dél, pero diferentemente de Petrarca». Así pues, al uso del terceto, se incorpora la epístola, la sátira ariostesca, la elegía, los mórbidos afectos eglógicos y el capítulo. Así lo reflejará Sánchez de Lima en la primera métrica petrarquista española, su Arte Poético de 1580: «los tercetos sirven para tratar larga materia, como es una epístola, o narración, una elegía y cosas de esta calidad».

7 Literaturas Italiana y Española Frente a Frente, Madrid, Espasa Calpe, 1978.

8 Ibíd., pág. 160.

9 Ibíd., pág. 161. 
En 1543, cuando aparecen las Obras de Boscán y Algunas de Garcilaso de la Vega, nos encontramos en tercetos las siguientes composiciones: dos capítulos de Boscán, la epístola de Hurtado a Boscán y la respuesta de éste. De Garcilaso figuran las dos elegías y parte de la égloga segunda. La publicación de esta obra es el aldabonazo decisivo para la consolidación definitiva del terceto en España, como lo indicaría Hernando de Hozes en la introducción a la traducción en tercetos que él mismo realiza de los triunfos.

Podemos decir que Cetina ensayó cuantas composiciones se prescribían en tercetos. Y en efecto, entre su producción en este metro encontramos dos capítulos: el primero «Diga quien dice y quien alaba alabe». Este capítulo tiene como fuente directa una elegía de Ariosto ${ }^{10}$. Una vez más la imbricación de la elegía en otro género se hace patente. El segundo «Si cosa he dicho ya en que a vos ofenda» es, igual que el primero, una apología del amor por ingrato y doloroso que éste sea.

Continuando la revisión del panorama del corpus epistolar de la obra del poeta sevillano, llegamos al grupo que en la clasificación de Begoña López es denominado «otros temas». Entre estas epístolas hallamos la enviada a la princesa de Molfeta, próxima al capítulo bernesco y en la que Cetina le propone a la princesa que prepare una olla podrida con los presentes de sus amigos. Otra de estas composiciones va dirigida al príncipe de Ascoli; en ella le da noticia al príncipe de su nuevo modo de escribir abandonado ya el «furor de los furores». Otra de éstas, enlazada en su crítica anticurialesca a las anteriores y a la dirigida a Hurtado, es la enviada a Baltazar del Alcazar, en respuesta a una que este le escribiera quejándose de los sinsabores de la vida en el campo. En ella el poeta intenta persuadir a Baltasar de León de las ventajas que la vida en la aldea ofrece sobre la vida en Sevilla, ciudad sobre la que se lanzan todas las saetas de la tópica anticortesana.

En este grupo de clasificación de Begoña López hallamos también dos de las epístolas publicadas por Lucas de Torre. La primera, llamada «Epístola y enfados de Cetina», va dirigida a un personaje anónimo y es una enumeración de personajes tipo y oficios: astrólogos pedantes, capellanes, soldados, mercaderes, etc. La segunda es la «Epístola a un compadre», con la siguiente explicación: «trata del amor de la nescia y hermosa y de la fea y sabia». En ella intenta poner de manifiesto las bondades de la mujer necia frente a los que creen firmemente en la certera elección de la mujer sabia. Ambas responden a las características propias de las composiciones que históricamente venían denominándose sátiras. La identificación entre satira y epístola supone, con toda seguridad, uno de los obstáculos más difíciles de superar para la voluntad teórica de definir y caracterizar un género como la epístola. Históricamente ha sido aceptada la identificación referida a la sátira clásica. Así lo ha hecho notar la más prestigiosa bibliografía en relación al género clásico. Niell Rudd, —en la obra más extensa y precisa dedicada

10 Cfr. LÓPEZ BUENO, Begoña: ob. cit., ed. cit., pág. 112. 
a la sátira romana, en los últimos años: Themes in Roman Satire ${ }^{11}$ - declara en el prefacio de su obra «Nevertheless, the satirical spirit does appear from time to time, in any general discussion of roman satire the Epistles ought not to be neglected». Este deseo de no desatender el estudio de la epístola en el tratamiento de la sátira era abrigado por la obra clásica de Fiske: «In fact, these satires of the second book with their more systematic presentation of the questions of social ethics are in content the direct precursors of the first boock of the epistles» ${ }^{12}$.

El entrelazamiento de ambos géneros es el factor que determina no sólo el parentesco temático y formal de uno y otro, sino también la obligación de estudiarlos conjuntamente. Rudd, en su obra antes citada, estudia los núcleos temáticos sobre los que se articula la sátira romana, y el predominio de unos temas sobre otros en las distintas composiciones y en los distintos autores. Lo primero que constata Rudd es que estos núcleos temáticos coinciden con los de la epístola, así como hace notar la flexibilidad de su funcionamiento en el interior de cada composición: «Roman satirits may be thought as funcioning withing a triangle of which the apices are (a) attack, (b) entertainment, and (c) preaching... And of course attack, entertainment and preaching are themselves very loose and flexible terms». Ante esta total identificación entre ambos géneros, es lícito pensar que la denominación de sátira sea la más extendida, ya que la epístola era considerada como una derivación de la sátira. Entre otras razones, autores postclásicos como Sidonio y Persio gozaron de una notable difusión en la Edad Media. En el Renacimiento, la acre y elocuente sátira social en verso de Juvenal hace las delicias de Berni o Alamanni en Italia o de Regnier y Rabelais en Francia. Asimismo, la fórmula ridentem dicere verum ingresa en la tópica de las preceptivas como el principio informador de la comedia y de la sátira. Todo ello pesa sensiblemente en la desconsideración que nuestros tratadistas poéticos tuvieron para con la epístola. Pero esta desconsideración es disculpable por la rigidez que la poética aristotélica imponía sobre los criterios de los nuevos preceptistas continuadores del estagirista. Los criterios taxonómicos de clasificación de las obras poéticas atendiendo a la materia, al instrumento y al modo de imitación eran insuficientes y, naturalmente, una rémora insalvable para el análisis certero de una realidad poética en continuas transformaciones que poco o nada tenía que ver con las leyes que gobernaron la literatura clásica.

Esta desproporcionada inadecuación es la que obliga al preceptista neoaristotélico de más enjundia, Cascales, a omitir la epístola del contenido de las $T a$ blas Poéticas. En esta obra trata de la sátira como una «especie» dentro de la poesía heroico junto con la égloga y la elegía, porque «para su perfectión no se requiere canto ni baile» ${ }^{13}$. Observaremos, como en esta primera clasificación ingenua e insustancial a los ojos de hoy agrupa a la elegía y la égloga atendiendo al instrumento de la imitación lenguaje y otros medios como la música. Si se avanza

11 London, 1986, paǵ. XI.

12 Lucilius and Horace, Hildeshein, 1966, págs. 425-426.

13 Ed. de Benito Brancaforte, en Espasa Calpe, (col. Clásicos Castellanos, n. 207), Madrid, 1975, pág. 172 . 
en la caracterización de la sátira que nos propone Cascales, podremos constatar que, con tales criterios, sátira y epístola tienen necesariamente que coincidir. De tal manera que en cuanto al modo de la imitación: «la nueva sátira es imitación de una visiosa y vituperable actión, con versos puros y desnudos, para enmendar la vida. Entienda, pues, el satirógrafo que no es su oficio decir mal morder como fin de esta poesía, sino corregir vicios...» ${ }^{14}$. Para Cascales, más atento en su humanismo a la antigüedad clásica que a su propia contemporaneidad, no podría haber en la epístola más que una derivación de la sátira: «Horacio, que aun el nombre dellas le quitó y abrogó totalmente de sus obras, llamándolas, ya epístolas ya sermones» ${ }^{15}$.

Algo similar ocurre en la otra gran poética de nuestro siglo de oro, la Philosofia Antigua Poética (1596). En la obra del Pinciano se observa un tratamiento de la sátira semejante al de las Tablas. En la Philosofia Antigua, sin embargo, se incluye la sátira entre los géneros poéticos menores. Son someramente descritos la mímica, la égloga, la elegía, el epigrama y el apólogo; excluyendo, curiosamente, de este catálogo a la epístola. Se debe pensar por tanto que sátira y epístola eran para la formación aristotélica del polígrafo vallisoletano una misma cosa.

No es necesario, pues, abundar más en los impedimentos que las leyes que rigen los criterios de clasificación de la obra literaria suponen para analizar sátira y epistola como dos géneros que se complementan, y no confundidos en uno solo: la sátira.

Llegados a este punto, nos vemos en la obligación de adentrarnos en el análisis de la epístola que Cetina dirige a Hurtado de Mendoza. De su estudio se intentarán extraer algunas de las leyes que organizan y determinan las estructuras de la epistola poética. Cuando nos preguntábamos qué era la epístola para Cueva, nuestro asombro no respondía más que a la inadecuación que revelaba aquella ambigua y prolija confusión de géneros y la idea que tenemos formada hoy, con la distancia crítica que el tiempo procura, de tal género. Cuando el estudioso de hoy repara en la epístola como género poético, se ve remitido súbita y espontáneamente a las epístolas de Bartolomé Leonardo de Argensola al Marqués de Cerralbo, la dirigida a Fernando de Borja, virrey de Aragón, o bien pensamos en la pureza, perfección y armonía de los tercetos de la Epístola Moral a Fabio de Andrés Fernández de Andrada; considerada esta como emblema de un género: la epístola moral.

Lógicamente, las diferencias entre la epístola moral cultivada en el siglo XVII y la que Cetina envía a Hurtado son notables. Ahora bien, las coincidencias entre una y otra son tan sensibles que se puede afirmar que la composición de Cetina, junto con algunas de sus contemporáneos de las mismas características, representa el modelo de composición de un género rigurosamente nuevo, nacido en el seno del humanismo poético español ${ }^{16}$, destinado en su trayectoria de perfeccionamiento a desembocar definitivamente en la epístola moral del siglo XVII. Ha-

14 Ibíd., pág. 180.

15 Ibíd., págs. 180-181.

16 Cfr. RIVERS, Elias L. y GUILLÉN, Claudio: Art. cit. en ob. cit. 
bría que pensar, pues, que los rasgos genéricos que a continuación vamos a estudiar representarían un primer estado de formación de este género.

Al tratar de la indiferenciación de sátira y epístola entre los antiguos, y considerar la segunda como una derivación de la primera, habría que estimar que tal derivación arrastraba consigo algunas de las características distintivas que la hicieran posible. La primera y fundamental diferenciación se centraba en el destinatario explícito de estas composiciones. Para la sátira, en la mayoría de los casos era el lector; para la epístola, generalmente, un amigo próximo en ideas y sentimientos al autor. "The epistles — escribe Fiske-, indeed, are simply a subdivision of the satiric form. Like the satires they are not poetry in the strict sense of the term. They are sermones in the sense that they are discourses, but while the satires are the sermones adressed directly to the readers, the epistles are either real letters addressed to some menber of the poet's circle of friends, or else they are discourses to the general public presented under cover of an introduction to a friend in the epistolary form ${ }^{17}$.

La calidad del destinatario permitiría un primer grado de diferenciación entre la «Epistola y enfados de Cetina», cuyo destinatario es una persona desconocida, o lo que es lo mismo, el lector en su sentido más amplio, la «Epístola a un compadre», recogiendo bajo esta feliz denominación burlesca al mismo destinatario que la anterior; y las dirigidas a Baltasar del Alcázar, el príncipe de Ascoli y Diego Hurtado. En estas tres últimas la coincidencia rigurosa entre el yo de la enunciación y el yo del enunciado como elemento primordial del estatuto expresivo - el modo exegemático para la preceptiva neoaristotélica- condicionará completamente la estructura de la composición. En primer lugar, determina las características del exordio y del final. Ambas partes de la arquitectura de la composición abundan en detalles personales, en recursos retóricos tendentes a la captatio benevolentiae y en la casi deificación de la amistad. Este es el rasgo más pertinente de las epístolas familiare e iocosum de Cicerón, como aparece en la carta a Curio ${ }^{18}$. Pero será Horacio quien lo convierta en característica de género en sus epístolas en verso. Elias L. Rivers considera la insistencia en el tema de la amistad y la proliferación de detalles personales como los rasgos típicamente horacianos que mejor adapta Garcilaso en su epístola a Boscán.

La epístola de Cetina a Hurtado de Mendoza tiene una extensión de 298 versos, con un dilatado exordio de 51 versos y un final al que le dedica 30 versos de despedida. En total el número de versos es casi un tercio de toda la composición.

El principio de la epístola nos lleva directamente a lo que hemos denominado deificación de la amistad:

Si aquella servitud, señor don Diego que con vos tuve, agora no tuviese sería de saber muy falto y ciego.

17 Ob. cit., ed. cit., pág. 426.

18 DILKE, O. A. W.: Horace, London and Boston, 1973, pág. 95. DILKE, O. A. W.: «Horace and the verse Letter», en Varios, Horace, London... 
Hazañas refiriéndose al término servitud, señalaba que debía entenderse como dependencia trocada en amistad. Pero Batallón estimó que el origen de esta palabra se encontraba en el italianismo «servitú», propio del lenguaje cortesano y amoroso.

A continuación pasa a exponerle a Hurtado la causa que le ha impedido escribirle antes; ésta es el mal de amor. En la propia indignación por su inactividad poética halla el impluso decisivo para coger la pluma:

Lo que Febo hallar dificultoso suele, la indignación ha hecho llano

La imitación de un género como la epístola y la facilidad que el terceto dispensa para la amplificación, le permiten a Cetina extenderse a lo largo de treinta versos en la persuasio propia del exordio.

Las dudas acerca del sujeto de la epístola acentúan la intensa presencia en el enunciado no sólo del yo, sino también del tú del destinatario:

Que no sé yo qué os escriba que os agrade, que puede al gusto vuestro ser sabroso

Seguidamente cita la excelsitud de las dos grandes luces que guían los pasos poéticos de su generación: Garcilaso y Boscán. Es entonces cuando aparece la $h u$ militas de Cetina frente al hacer poético de Hurtado de Mendoza, quien aparece en lo más alto del monte Parnaso, libando no ya en el surtidor de la fuente Castalia, sino paciendo del manjar divino de la poesía:

Yo que a volar he comenzado apena, apenas oso alzarme tanto a vuelo, que no lleve los pies por el arena. Vos, remontado allá casi en el cielo, paciendo el alma del manjar divino.

Quien sabe si queréis mirar al suelo?

Desembarazado el poeta de los severos rigores de la retórica del exordio, en el final de la epístola el discurso se vuelve mucho más dialogístico y lo confidencial se adorna sólo de naturalidad, si bien las fórmulas de tratamiento permanecen:

Y de todas las cosas que pregunto

con el primero me enviad respuesta

cual la deseo yo, cual la barrunto

que, pues mi servitud está tan presta (...)

(274-277)

Igualmente se introducen detalles personales concretos que en muchas ocasiones representan una fuente de inagotable valor para la historia literaria.

De tal modo le expresa Cetina a Mendoza el deseo de ver una pintura de Tiziano, donde está representada Primavera, que hacía tiempo ansiaba contemplar. Probablemente este cuadro fuera el retrato de doña Marina de Aragón, la Marfi- 
ra del cancionero de don Diego. De este cuadro da noticia Aretino en una carta y en un soneto que la acompañaba. Ya que el cuadro no se conoce es posible pensar que la Primavera apareciera personificada en doña Marina, pues Tiziano no tiene entre sus obras catalogadas ninguna representación o alegoría de la primavera tan frecuentes en la iconografía del Quinientos:

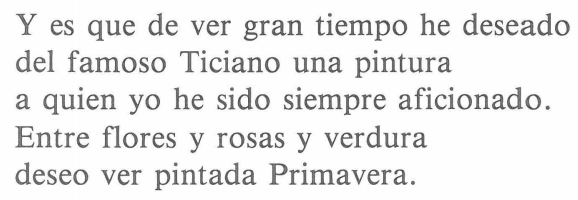

La despedida responde al tono de cordialidad, de afecto y de confianza, próxima a la connivencia, del tú y el yo:

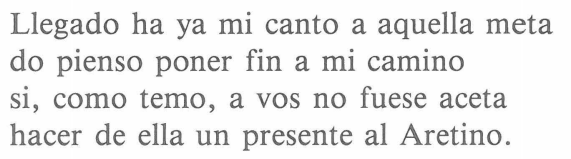

(295-298)

La presencia constante, pues, del yo del enunciado define las características del exordio y del fin de la epístola por ser la expresión de una sensibilidad proyectada a un destinatario reconocido como amigo.

La univocidad del yo de la enunciación y del enunciado, así como la relación pronominal del autor y el tú del destinatario, determinará, igualmente, el criterio estilístico de la epístola.

En la sátira, el enmascaramiento del poeta y la presencia de un yo impersonal que se dirige a un destinatario colectivo (oficios, estados, etc.) atacado por los males y vicios de la sociedad, permite la transgresión de las leyes del decoro y en consecuencia la tendencia al estilo bajo tan apto para el relieve de lo grotesco, lo cómico y lo vituperable en general. En la epístola, sin embargo, el autor se muestra a cara descubierta y la primera persona le responsabiliza de todo cuanto dice. De otro lado, la calidad del destinatario (amigos de su círculo o personas generalmente superiores socialmente) obliga a utilizar un registro idiomático que impedirá subvertir las reglas del decoro. Esta adaptación del estilo a las condiciones del destinatario es algo que destaca Dilke en las epístolas horacianas: «It is clear that in at least cases the poet carefully adapted his language to the interests and background of his addresse» ${ }^{19}$.

No obstante, podemos reconocer en las epístolas algunos descensos al sermo humilis, así como la elavación del tono a notas más elevadas de estilo, tal como señala Claudio Guillén frente al estilo bajo de la sátira, «lo propio de la epístola es el estilo mediano, en lo esencial, pero también dar cabida lo mismo al estilo simple que al elevado». ${ }^{20}$.

19 Ibíd., pág. 102.

20 GUILLÉN, Claudio: art. cit., pág. 228. 
Sin embargo, el problema del estilo es el más complejo en lo que atañe a la caracterización del género por la falta de uniformidad en los criterios estilísticos que guían a los poetas del XVI a la hora de componer una epístola.

Esta consideración previa nos lleva directamente al verso más enigmático del poema que nos ocupa:

Mas antes de volerme del camino
acuerdo de decir alguna cosa
en estilo grosero o peregrino
$(49-51)$

Si se considera este verso como una sentencia disyuntiva por la cual Cetina debe elegir entre un estilo grosero, o bien peregrino, el asombro ante tal duda, por parte del poeta, nos confundiría, pues ambos términos representan polaridades totalmente opuestas. A nadie se le oculta que el estilo grosero se identifica con el sermo humilis. Sin embargo, tradicionalmente el estilo peregrino se ha venido emparentando con la alteza propia del estilo heroico, con las voces inusitadas, así como con los neologismos. En el Pinciano constatamos como el vocablo «peregrino» es parte importante en la distinción del lenguaje poético del de uso normal: «Vocablo peregrino se dize el que es fuera de uso, el qual, o es desusado o peregrino del todo, como el vocablo arábigo o griego al francés,...» ${ }^{21}$. Es, igualmente, un factor de oscuridad: «mirad —escribe el Pinciano- como lo será que, allende que es la poética peregrina y de vocablos peregrinos y escuros» ${ }^{22}$. Para Fadrique la poética «debe tener alto lenguaje y peregrino», y en otro lugar: «nacióle la grandeza de los peregrinos vocablos, y en esto no hay que dudar» ${ }^{23}$.

Es, por tanto, manifiesto que la naturaleza propia de la poesía exige el lenguaje peregrino, el cual está directamente vinculado a la grandeza.

Pero es en el seno de la polémica gongorina donde el término peregrino adquiere relieve para caracterizar la alteza del lenguaje poético. Díaz de Rivas, armado de toda la tradición retórica y poética: Aristóteles, Quintiliano, Minturno, Budeo, Cicerón, etc., escribirá en sus Discursos Apologéticos: «Con esto alcanzó nuestro poeta [Góngora] dos fines, el uno versos nada groseros..., lo segundo consiguió un frasi realzado y peregrino» ${ }^{24}$. Dirá después: «Y si nuestro poeta para hablar con sublimidad desechó todas las voces humildes y frasis vulgares, no sólo por el ornato, sino como por necesidad metió la mano en las delicias y pompas del lenguaje peregrino» ${ }^{25}$. En los mismos términos y amparados en las mismas autoridades, escribe el abad de Rute en su Parecer: «El hablar figurado, demasiadamente y con palabras peregrinas engendra el estilo sublime; testigos Aristóteles, Scaligero, Torquato» ${ }^{26}$.

21 LÓPEZ PINCIANO, José Alonso: Filosophia Antigua Poetica, ed. Alfredo Carballo Picazo, Madrid, C.S.I.C., II, pág. 126.

22 Ibíd., pág. 127.

23 Ibíd., pág. 130.

24 Discursos Apologéticos, ed. de Eunice Joiner Gates, México, Colegio de México, 1960, pág. 44.

25 Ibíd., pág. 44.

26 En OROZCO DÍAZ, Emilio: En Torno a las Soledades de Góngora, Granada, 1964, pág. 137. 
Se nos presentan tan equidistantes los términos de la oposición grosero/peregrino que se hace difícil admitir la formulación de este verso como una disyunción. A nuestro juicio, conviene más, no sin cierto funambulismo gramático, entender la conjunción «o» como distributiva:

Acuerdo de decir alguna cosa

[ora] en estilo grosero, [ora] en estilo peregrino.

Si volvemos los ojos a la epístola que Cetina dirige a Baltasar del Alcazar, allí encontramos una declaración de principios estilísticos que nos hará admitir sin ningún género de dudas la interpretación dada a tan confuso verso. Escribe Cetina en la epístola Alcázar:

No le busquéis pulidas perfecciones

Ni sombras, ni luz clara $^{27}$ que, en efecto

Es un simple conjunto de carbones

Bien que entre lo grosero y lo perfecto

«Grosero o peregrino», «entre lo grosero y lo perfecto». Ambas oposiciones evidencian las posibilidades estilísticas, capaz de elevarse a altas cotas de lirismo y descender al estilo bajo. Y efectivamente, Cetina, en su epístola a Mendoza, después de describirle la toma de Duren por parte de los ejercitos imperiales y mientras expone el sitio de Landrecies en el tono sobrio y grave que tal narración merece, introduce el siguiente verso en toscano:

Mala rima mi forza a dir cacata.

Al margen del significado del verso, que no necesita explicación, es conocida de todos la condena unánime por parte de los preceptores de la introducción de versos en lengua extranjera. Así censuró Herrera el último verso: «Non essermi passato oltra la gonna» del soneto XXII de Garcilaso: «No puedo dejar de decir aquí que es vicio muy culpable entremeter versos de otra lengua» ${ }^{28}$. En los mismos términos se expresa Cueva en el Ejemplar:

Cuando en Vulgar de España se razona no mezcles verso extraño, como Lasso.

$(259-260)$

A pesar de la dificultad que entraña precisar los criterios estilísticos, la reflexión última que nos plantea el discutido verso 51 («en estilo grosero o peregrino») es que la duda, la perplejidad e incluso la confusión de Cetina revelan el esfuerzo teórico por parte de los poetas de esta generación de trazar los límites de este género, y del resto de los géneros neoclásicos, en el desarrollo de su gestación. El origen de este verso hay que conectarlo con los motivos que impulsaron

27 Las palabras subrayadas a la recontrucción del manuscrito hecha por Hazañas.

28 Anotaciones en GALLEGO MORELL, Antonio: Garcilaso de la Vega y sus Comentaristas, Madrid, Gredos, 1972, pág. 368. 
a Garcilaso a la figura correctionis del terceto de la elegía II, que dieron pie al admirable artículo de Claudio Guillén.

$$
\begin{aligned}
& \text { Mas, donde me llevó la pluma mía? } \\
& \text { que a sátira me voy mi paso a paso, } \\
& \text { y aquesta que os escribo es elegiía. }
\end{aligned}
$$

La misma figura correctionis y las mismas causas le hacen escribir a Cetina en su epístola a Baltasar del Alcázar:

Mejor será callar, puesto que el caso

a escribir más satírico me tira.

Volviendo a la relación entre el sujeto de la enunciación y el sujeto del enunciado, encontramos el papel decisivo del yo en los núcleos temáticos de la epístola. El yo, conformado como voz y punto de vista crítico del poeta, regirá la estructura y desarrollo del discurso, dotando de realidad vivida las ideas abstractas. Desde la atalaya privilegiada de la primera persona, se articularán los dos ejes centrales de la composición: la narración de la batalla de Duren y el sitio de Landrecies, primero, y la crítica anticurialesca después. La participación de Cetina en la batalla de Düren —en la cuarta guerra contra el rey de Francia (15431544) - al lado de Fernando Gonzaga (nuevo Marte) y el emperador, permite que el relato de los hechos, se escriba en su exacto desarrollo, plagado de escenas y hechos precisos, aunque enturbiados, en la mayoría de los casos, por matices truculentos y tintes de sangre hiperrealistas. Es, en fin, la narración de alguien que ha visto y vivido en su intensidad tales hechos y desea poner de manifiesto - ante el amigo- su presencia en el escenario real de la batalla. Así pues, escribe Cetina a Mendoza: «La empresa que este año a César hecho» (v. 53) ${ }^{29}$, precisándonos con exactitud su desarrollo:

En un asalto, sin tomar sosiego

el cual duró cuatro horas, poco menos.

En otras ocasiones - como se ha dicho- el poeta se recrea en el efectismo de algunas imágenes:

Allí de cuerpos muertos se vían llenos

los fosos; palpitando las heridas.

La utilización del presente histórico actualiza y viste de realidad lo acontecido:

Carlos Quinto lo llama y lo importuna,

y ofrece la batalla...

En los versos finales dedicados al relato del sitio de Landrecies, se pone de manifiesto hasta qué punto el diálogo establecido entre autor y desinatario condiciona la estructura y el contenido de la epístola. Al referirse a la actuación de los

29 Este dato nos sirve para fechar la Epístola en 1543. 
caballeros en el campo de batalla, Cetina le muestra a Mendoza sus reservas respecto al comportamiento de algunos:

Lo bueno yo no sé si no alaballo;

si algo hubo de mal, que nunca falta, a la presencia pienso reservallo.

La relación confidencial, la amistad que une a ambos en sentimientos e ideas hacen al poeta silenciar las razones políticas e ideológicas que mueven esta guerra. Es obvio pensar que tales motivos no era necesario explicitarlos a Mendoza, hombre vinculado durante muchos años a los destinos de la política imperial. Sin embargo, es pertinente observar que, desatado de las ligaduras del género epístolar, en un soneto dedicado al conde de Feria, — participante en la campaña militar —, aparezca el contenido ideológico y religioso de la cuarta guerra contra el rey de Francia:

Mientras el franco furor fiero se muestra en uno con el bárbaro tremiendo, mientras el consorcio protestante, horrendo

turbar piensa la fe y la patria nuestra, (... $)^{30}$

Precisamente, la figura del Conde de Feria, Gómez Suárez de Figueroa, importante hombre de la administración, consejero de estado y de la guerra, sirve para introducir en la epístola el segundo de sus núcleos temáticos, la crítica anticurialesca:

Pensé deciros del novel de Feria

Cómo con su valor ha desterrado

Desta corte los vicios y miseria.

$(157-159)$

La reflexión sobre los vicios de la corte, lugar donde se concentran, en comunión, metaforizadas las debilidades y miserias del hombre, entronca con el principio genuinamente epistolar: la filosofía moral. En el hilo conductor que une la epístola horaciana de Garcilaso a la Epístola Moral a Fabio, la filosofía moral constituye el rasgo distintivo que las identifica como obras de un mismo género, y, por ende, las separa de sátiras, capítulos, elegías, etc. Este ingrediente de reflexión, de predicación filosófica era también marca diferenciadora de la sátira romana y la epístola en Horacio, al respecto escribe Rudd: «For a poem wich has its position somewhere along the line (b) - (c) (entertainment-preaching) does not count as a satire. Many of Horace'Epistles are on or near that line» ${ }^{31}$.

Cuando decíamos que la primera persona articulaba los dos núcleos temáticos de la epístola de Cetina, esta afirmación no afectaba sólo a la forma en que se estructuraba la composición, sino también al sentido último de la epístola. El yo del poeta, presente explícitamente en el enunciado, nos aproxima su punto de

30 CETINA, Gutierre de: Sonetos y Madrigales Completos, ed. Begoña López Bueno, Madrid, Cátedra, pág. 303.

31 Ob. cit., ed. cit., pág. 1. 
vista en la observación de la realidad. Su función no es otra que legitimar su visión del mundo a través de la experiencia.

$$
\begin{aligned}
& \text { Yo, que, por experiencia, conocida } \\
& \text { tengo la corte ya, voime riendo } \\
& \text { de quien sigue tras cosa tan perdida. }
\end{aligned}
$$

En una época como el Renacimiento, en que el idealismo y la actitud crítica frente a lo real — basada en el subjetivismo y el uso autónomo de la razón-, la importancia del yo no puede ser medida sólo en su dimensión retórica y estilística, sino también como el valor supremo y único capaz de avalar y legitimar en sus opiniones el discurso. Es la divinización del subjetivismo, arrastrando tras de sí el punto de vista y el perspectivismo, lo que posibilita en el Renacimiento el nacimiento de la novela moderna. Del mismo modo, la injerencia del yo en la reflexión filosófica y moral define los rasgos específicos del género epistolar.

La epístola viene a ser el vehículo a través del cual el poeta nos expresará sus sentimientos más hondos, sus preocupaciones sociales y filosóficas más íntimas. En definitiva, es en la epístola, en la recia urdimbre entre el sujeto del enunciado y el sujeto de la enunciación, donde el poeta se nos revela como hombre. Los poetas del XVI obstinados contumazmente en la poesía amorosa del índole petrarquista o en los juegos conceptistas que proporcionaba la poesía cancioneril de raíz tradicional, no contaban en el dominio de sus posibilidades métricas y estróficas con un género que le permitiera la expresión dilatada y reposada de su visión del mundo. Ese es el espacio que viene a ocupar la epístola. Aún a pesar de la peripecia de su desarrollo, la evolución de la epístola desde Garcilaso hasta la epistola moral del XVII no se detiene por su condición de género necesario. Como señala Begoña López: «La visión de la vida de corte, fundada en falsos valores necesitaba en su transposición a contenidos literarios de vías distintas a los caminos del petrarquismo» ${ }^{32}$.

Para quien sólo ha leído la obra petrarquista de Cetina, difícilmente podrá reconocer al poeta sevillano en los versos de la epístola a Mendoza. En ella nos encontramos - parafraseando el título de la obra de Begoña López- con el Cetina, hombre del Renacimiento.

$* * *$

La crítica anticurialesca en nuestra literatura se va a desarrollar por distintos caminos. De un lado la literatura ascética de raigambre cristiana del humanismo castellano del siglo XV, unida al estudio de autores como Séneca y Cicerón, dará obras como De Vita Beata (1463), de Juan de Lucena, que inserta el tema del menosprecio de corte en el humanismo cristiano.

De otro lado, está el componente senequista y epicúreo vertido en obras como De las Miserias de los Cortesanos de Enea Silvio, traducido por Diego Lope de Cortegana y publicado junto a la Querella Pacis de Erasmo de 1520 en Sevilla. Asimismo, la tradición del beatus ille, desde Virgilio a Horacio, no sólo como recreación del tópico sino como ideal de vida.

32 Ibíd., pág. 43. 
Igualmente cuentan los poetas del XVI en la tradición con obras concretas referidas al tema, como la casi totalidad de los tratados del curioso Fray Antonio de Guevara, o antes Sánchez de Arévalo en Espejo de la Vida Humana, obra de 1491.

Por estos cauces penetra el tópico del menosprecio de corte en el humanismo español del XVI, personalizándolo después cada autor de forma original.

Cetina por medio de preguntas retóricas como : «Qué os parece?» o «Qué decís?», que se repiten alternativa o consecutivamente, enumera todos los vicios de los cortesanos: ambición, envidia, hipocresía, ostentación... Pero para él todos estos males tienen su origen en la vanidad:

El humo y vanidad de aquesta corte

me tienen puesto en confusión y espanto

(164-165)

El tema de la vanidad está presente en toda su crítica. En el Renacimiento este tema se carga de complejidad. El significado de la vanidad no sólo nos remitirá al sentido que la Edad Media encontraba en el exordio del Eclesiastes; el vanitas vanitatis de tanta raigambre en nuestros poetas del $\mathrm{XV}$, por el que todo lo terreno no constituía sino un falacia de la auténtica verdad que era la muerte y la conciencia de la verdad suprema que es Dios. La tradición estoica incidirá en este sentido y procurará a su filosofía la necesidad de aislarse del mundo sensible, rechazando los afectos. Sin embargo, el humanismo concederá a la vanidad una nueva dimensión filosófica, ya que su significado va unido a las apariencias, el humo, la ilusión. El Renacimiento, como ya se ha comentado, abre el camino hacia una teoría del conocimiento en la que lo primero que hay que considerar es -en feliz expresión de Don Américo Castro- la realidad oscilante. En este sentido se expresan Vives, Castiglione, Bembo, o Erasmo: «Para decir la verdad, - escribe Erasmo - todo en este mundo no es sino una sombra y una apariencia; pero esta grande y larga comedia no puede representarse de otro modo».

Y en este sentido habría que conectar el verso 164 de la Epístola con los siguientes tercetos:

Y digo que es la corte, si la entiendo, una cierta ilusión, una apariencia que se va poco a poco deshaciendo.

De la corte no hago diferencia

al espejo, que muestra algunas cosas, graves, que nada son esistencia.

(259-264)

Trata Cetina en su epístola temas típicamente renacentistas como la oposición vulgo/sabio:

El cortesano cuerdo y avisado

que no quiere nadar con la corriente

del vulgo me decid: cómo es tratado?

(220-222)

Cetina expresa en el vulgo todo su desdén por la masa ignorante -entre ellos los ambiciosos cortesanos-y la supremacía moral del docto. El vulgo es el tér- 
mino de la oposición que sirve para sobrevalorar al sabio. Escribe Américo Castro: «Hay tal conciencia del valor de la cultura, es tan potente y moderna su victoria, que no es de extrañar que la minoría que inventa y construye el mundo nuevo ostente un orgullo ingenuamente pedantesco» ${ }^{33}$. Cetina participaba de la fe en la cultura expresada por Castro.

El binomio renacentista de las armas y las letras aparece expuesto en forma de amarga queja:

Han convertido el juego en ejercicio común, juegan los grandes, los plebeos; armas y letras van ya en precipicio.

En los mismos términos lo expresa en la epístola a Baltasar del Alcazar:

Los entretenimientos más usados destos, armas no son, letras ni amores más el juego, las cartas y los dados.

El ideal del cortesano y el caballero ilustrado cede su paso a la corrupción. Pero en verdad, Cetina está constatando la desaparición de la figura ideal el poetasoldado que él representa; por ello su lamento está cargado de rabia. El discurso sobre las armas y las letras del Quijote es fiel reflejo de la desaparición del binomio tradicional, por el peso del anacronismo en la caracterización del personaje cervantino. En este debate participan todos los humanistas de la época: Bembo, por boca de Castiglione; Erasmo, en todo momento en favor de las letras; o la conocida opinión de Mallara: «La pluma no embota la lanza».

La corte aparece en la epístola como el escenario donde los cortesanos se devoran por llegar a alcanzar la ansiada prebenda que esperan de la fortuna:

Por llegar a aquel grado que desea

qué vida tan estrecha y trabajosa!

Qué parecido entre estos versos y el contenido del arranque de la Epístola Moral a Fabio:

Fabio las esperanzas cortesanas prisiones son do el ambición mora y donde al más activo nacen canas.

El cortesano actúa de acuerdo con los demás sin seguir lo que dicta la razón. Seguir a la opinión implica renunciar a la obligación moral de uno para consigo mismo:

El otro con envidia urde y rodea.

Observamos ahora como la actitud de renuncia del sabio recorre la estela del género epistolar en España. Dirá Boscán en la epístola a Mendoza:

33 El Pensamiento de Cervantes, Madrid y Barcelona, Noguer, 1980, pág. 210. 
Así que yo ni quiero ya, ni puedo

tratar sino de vida descansada

sin colgar de esperanza ni de miedo.

Escribirá Cetina:

Qué os parece, Señor, de la esperanza que grande se le muestra en perspectiva?

Cuán poco fruto, al fin, della se alcanza!

Finalmente, en la Epístola Moral a Fabio encontramos el siguiente terceto:

Más triunfos, más coronas dio al prudente

que supo retirarse, la fortuna,

que al que esperó obstinada y locamente.

La fortuna es el tema nuclear del menosprecio de corte. La fortuna encuentra su campo labrado en el mundo ilógico de la corte. Se produee un enfrentamiento entre el determinismo medieval y la búsqueda de la libertad humana que representa el Renacimiento. La fortuna conduce a la inestabilidad y al desequilibrio social:

Por qué hizo Fortuna desiguales sus leyes? Por qué es rico un avariento?

$(235-236)$

De esta sinrazón hablan también estos versos:

El que siendo ayer pobre, hoy se ve rico!

Tirano es hoy aquel que ayer era justo.

Incluso se nos muestra Cetina como representante del humanismo civil que tanto vigor tuvo en Italia y cuya ausencia en España pone de relieve Marguerita Morreale ${ }^{34}$. Podemos observar como nuestro poeta aboga por la necesidad de una justicia basada en la razón, capaz de nivelar los profundos y lacerantes contrastes sociales —véanse los versos 203-207 o 235-245-.

El somerísimo análisis del contenido de la crítica articurialesca en la epístola de Cetina a Hurtado sirve para hacer patente lo que hasta ahora hemos venido repitiendo. El poeta petrarquista no puede renunciar a su condición de hombre y de humanista; así pues, impregnado por su propia contemporaneidad ataca, denuncia y se rebela contra los problemas de su tiempo, adoptando para la expresión de su rebeldía el género epistolar.

Si alguna conclusión se puede desprender del análisis de la epístola de Cetina a Don Diego Hurtado de Mendoza, ésta es la evidencia de que Cetina, y junto a él todos los poetas que cultivaron la epístola en el XVI, tienen conciencia de 1959.

Cfr. Castiglione y Boscán: El Ideal Cortesano en el Renacimiento Español, Madrid, R.A.E., 
que sus epístolas son meros ensayos de un género que ellos mismos están creando en cada composición que realizan. Esta es la causa de las ambigüedades, perplejidades y dudas que con respecto al estilo manifestaba Cetina en el verso 51, parangonable con la figura correctionis de la elegía II e Garcilaso. Estos titubeos, pues, no eran más que la expresión de una voluntad teórico inclinada a fijar las leyes de un género caracterizado hasta entonces por la confusión.

Las causas de tal confusión tenían su origen en el procedimiento epistolar, valido para sátiras, elegías, capítulos, églogas y epístolas, y en el metro: el terceto. La adaptación del terceto en España arrastró consigo la flexibilidad genérica de la que este metro gozaba en Italia.

A esto habría que añadir el ejemplo difusor de la intercomunicación epistolar en latín entre los humanistas. La epistolografía disfrutó de una envidiable salud en el siglo XVI; así lo indican las varias ediciones que se hicieron del texto Illustrium Virorum Epistulae, de 1520, en el que se recogen cartas de Angelo Poliziano, Pico Mirandola y otros ${ }^{35}$. Habría que estudiar hasta qué punto el desarrollo del conocimiento dialéctico a través de la epistolografía humanística fue un factor inductor de la evolución de la epístola poética hacia la epístola moral.

Estas razones, entre otras, hicieron que Cetina denominara epístolas a la casi totalidad de sus composiciones en tercetos. Pero lógicamente, un género crece en el tiempo y su desarrollo se refleja en los tanteos e incertidumbres que nos han hecho considerar la epístola de Cetina a Hurtado como un ensayo en el género epistolar. En este camino de experimentación van cayendo muchas de aquellas composiciones que el género, en su proceso de perfeccionamiento y definición, había estimado en principio. Prueba de ello es que en las Flores de Poetas Ilustres de Pedro Espinosa, junto a un capítulo de Vicente Espinel al marqués de Peñafiel o una epístola de Andrés Rey de Artieda al marqués de Cuellar sobre la comedia, aparecen la mayor parte de las epístolas de Lupercio y Bartolomé Leonardo de Argensola, que representan el fin último al que se encamina el género epistolar en España: la epístola moral. Sin embargo, no aparecen en las Flores ninguna composición epistolar próxima a la elegía, al capítulo u otros géneros que bajo el nombre de epístolas se confundían en origen entre sí.

La epístola nace como alternativa al petrarquismo. Las canciones, los sonetos, formas dilectas de la lírica petrarquista, ahogaban en su geometría cualquier disgresión de contenido moral. El terceto proporcionaba un modo estrófico hecho para la amplificación, para el análisis extenso y grave de la condición humana del poeta y su alteridad.

Igualmente, el procedimiento epistolar facilita la solidaridad y la coincidencia entre el yo de la enunciación y el yo del enunciado como elemento esencial del estatuto expresivo. Nuestro estudio de la epístola de Cetina a Diego Hurtado de Mendoza se proponía constatar hasta que punto esta identificación entre el sujeto de la enunciación y el yo del enunciado condicionaba, en unos casos, y determinaba, en otros, los criterios estilísticos y temáticos del género epistolar y su estructura.

35 Cfr. PRIETO, Antonio: La Poesía Española del Siglo XVI, I, Madrid, Cátedra, 1981, págs. 176-181. 